\title{
Exploring the acute myeloid leukaemias
}

\section{Thapa $\mathrm{JB}^{1}$}

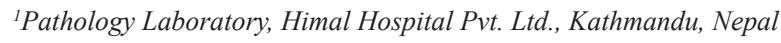

\section{Keywords:}

Acute myeloid leukaemia; Immunophenotyping;

Cytogenetics; Molecular genetics; Gene profiling

\begin{abstract}
Abstract: The acute myeloid leukemias are genetically a diverse group of neoplasm with varied clinical behavior and response to treatment. Advances in immunophenotyping, cytogenetics and molecular genetics have resulted in better understanding of their genesis. Risk stratification of different variants is now emerging. Therapy strategies are now increasingly being developed considering the inherent biological behavior of the different subtypes. It is anticipated that in the future, deeper secrets of these once fatal diseases will be unraveled by advances in newer genomic techniques. It is hoped that future use of gene specific tailored therapy and strategies will result in longer survival in cases showing poorer prognosis at present.
\end{abstract}

\section{History and classifications}

The classification and genetics of acute myeloid leukaemias (AML) have undergone major changes since the 1970's as rapid advances in immunology and genetics have made significant progress in the understanding of this varied group of disorders (fig. 1). The current 2008 WHO classifies precursor myeloid neoplasm into 7 major types and 24 subtypes' entities (Table 1). ${ }^{1}$

The first globally accepted AML classification was that of the French American British Classification (FAB; 1976) based on morphology and cytochemistry (\% blasts and maturation). ${ }^{2}$ The revised FAB; 1982 classification was similarly based on morphology and immunophenotyping. ${ }^{3}$ The WHO classification (2001) was based on morphology, immunophenotyping, cytogenetics and clinical presentation. ${ }^{4}$ The current WHO (2008) classification is based on morphology, immunophenotyping, cytogenetics, clinical presentation and molecular biology.

\section{Correspondence:}

Dr. Jung Bahadur Thapa

Consultant pathologist, Himal Hospital Pvt. Ltd, Kathmandu, Nepal

Email: jungbahadurthapa@gmail.com
The FAB; 1976 was a landmark classification in its days. It was essentially a morphological classification. Initially it was very useful as it standardized nomenclature used by different authors all over the world. Immunophenotyping was introduced in revised FAB Classification in 1982 to differentiate AML Mo from ALL and to diagnose M7. Cytogenetics and molecular genetics were not used. It did not consider MDS associated AML or prognosis (risk groups categorization).

The WHO (2001) classification was the second landmark classification which incorporated morphology, cytogenetics, molecular genetics and immunological markers of AML. It was an acceptable classification having prognostic value. It separated favorable leukaemias with balanced translocations which respond better to treatment from the unfavorable ones..$^{5}$ The unfavorable group included AML with:

- Complex karyotypes

- Partial or complete loss or deletions of chromosomes 5 and/or 7

- Multilineage dysplasia and

- Multi drug resistance. 
The WHO (2008) classification basically continues to use the same approach used as in WHO 2001 classification, but added other parameters. It starts with analyzing basic morphology and also incorporates clinical, morphology, immunophenotyping, cytogenetics and molecular genetics for diagnosis and classification. As a result the initial morphological diagnosis may sometimes have to be amended after further investigations parameter reports become available (fig.2).

\section{Immunophenotyping and karyotyping:}

Immunophenotyping is rapidly replacing cytochemistry to differentiate acute leukaemias. They are useful to confirm myeloid or mixed phenotypic acute leukaemia lineage (MPAL; fig.3). ${ }^{6}$ They are also useful to separate minimally differentiated acute myeloid leukaemia from acute lymphoblastic leukaemia and recognition of acute megakaryoblastic leukaemia. Strict criteria for immunophenotyping diagnosis need to be followed when investigating suspected MPAL as over use of immunophenotyping can lead to an over diagnosis of MPAL. About 50-60 \% of de novo AML show karyotype abnormalities. By karyotyping AML are classified into low, intermediate and high risk groups (Table 2). ${ }^{7}$ Many AML cases have however normal karyotypes can still have genetic mutations. MDS related AML are now better understood due to karyotyping.

\section{AML with recurrent genetic abnormalities}

They have been separated as a distinct entity as they are associated with characteristic clinical, morphological and immunophenotypic features that form a clinicopathologicgenetic entity having prognostic significance. ${ }^{8,9}$ The most frequent are $\mathrm{t}(8 ; 21), \operatorname{inv}(16)$ or $\mathrm{t}(16 ; 16), \mathrm{t}(15 ; 17)$ and $\mathrm{t}(9 ; 11)$.

Distinct morphological changes may be seen with some of the translocations. Translocation t (8:21) (q22:q12) AML cases may show blasts with perinuclear hofs and chunky pink cytoplasmic granules which can be misinterpreted as granulocytes (fig.5). Inv (16) (p13:1q22) and t (16:16) (p13.1:q22) cases may show abnormal eosinophils with large basophilic granules.

\section{Mutation analysis in AML}

There are two types of genetic mutations in AML. ${ }^{10}$ Class I mutations provide a proliferative and/or survival advantage and do not affect differentiation. They occur late in the disease or in relapse. They include: KIT, FLT3-ITD and FLT3-TKD. Class II mutations impair haematopoeitic differentiation and apoptosis. They occur early in the disease. They include: NPM1 and CEBPA (fig.5).

\section{Correlation of some mutations in AML with prognosis}

Table 1: WHO AML classification 2008.

Acute myeloid leukaemia (AML) and related precursor neoplasm

AML with recurrent genetic abnormalities

AML with myelodysplasia-related changes

Therapy-related myeloid neoplasms

Acute myeloid leukaemia, NOS

Myeloid sarcoma

AML in Down syndrome

Blastic plasmacytoid dendritic cell neoplasm

Table 2: AML risk group categorization

\begin{tabular}{ll}
\hline Risk group & Cytogenetic abnormalities \\
\hline \multirow{3}{*}{ Favourable } & $\mathrm{t}(8 ; 21)$ \\
& $\mathrm{t}(15 ; 17)$ \\
& $\operatorname{inv}(16)$ \\
& Normal \\
& $+8,+21,+22$ \\
& del $(7 \mathrm{q})$, del $(9 \mathrm{q})$ \\
& $11 \mathrm{q} 23$ abnormality \\
other structural/numeric \\
antermediate & abnormalities \\
& $-5,-7$ \\
& del $(5 \mathrm{q})$ \\
& Abnormal $3 \mathrm{q}$ \\
Adverse & Complex Karyotype
\end{tabular}

Table 3: AML with recurrent genetic abnormalities

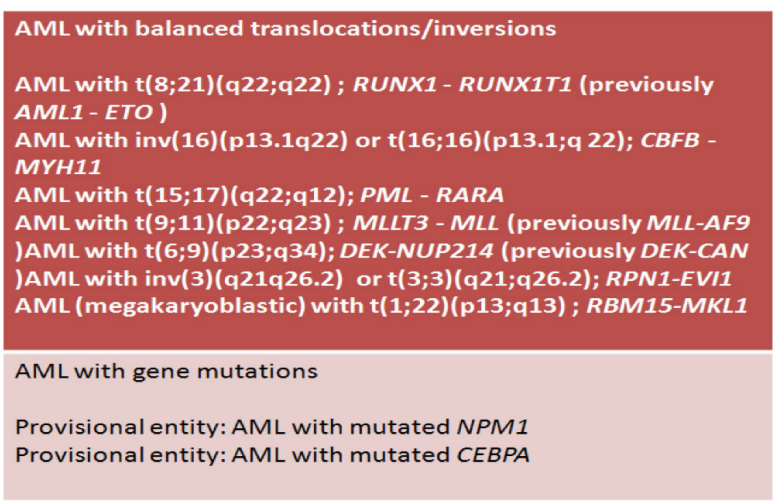

NPM1 (nucleophosmin) mutations are the most common mutations in AML They occur in 30\% of de novo AML and $50-60 \%$ of AML with normal cytogenetics. An NPM1 mutation without any FLT3-ITD mutation is associated with good induction therapy and better prognosis. ${ }^{11,12}$ CEPBA (CCAAT binding protein enhancer alpha) mutations are seen in about 5-9\% of AML. Lower relapse rate and improved survival are seen in CEPBA gene mutation. ${ }^{13}$ FLT3-ITD (FMS related tyrosine kinase 3 with internal tandem duplications) mutations are associated with shorter survival and unfavourable prognosis. ${ }^{14}$ KIT mutations associated with $\mathrm{t}(8 ; 21)$, inv $(16), \mathrm{t}(16 ; 16)$ are associated with poorer prognosis. ${ }^{15}$ Some of the other mutations and their present clinical utility are listed in table 4 . 
Table 4: Some gene mutations in AML and their significance

\begin{tabular}{llll}
\hline & Established & Likely & Potential \\
\hline $\begin{array}{l}\text { Favourable muta- } \\
\text { tions }\end{array}$ & $\begin{array}{l}\text { NPM1, } \\
\text { CEPBA }\end{array}$ & & \\
$\begin{array}{l}\text { Unfavourable } \\
\text { mutations }\end{array}$ & FLT3-ITD & KIT & $\begin{array}{l}\text { M L L - P T D, } \\
\text { WT1, FLT3- } \\
\text { TDK }\end{array}$ \\
$\begin{array}{l}\text { Unfavourable over } \\
\text { expression }\end{array}$ & & B A A L C \\
Clinical testing & Recommended & Optional ERG, & Investigational \\
\hline
\end{tabular}

\section{AML with myelodysplasia related changes}

These myeloid neoplasms include AML showing dysplasia: in more than $50 \%$ of cells of 2 or more myeloid lines in a pretreatment specimen. They can be seen de novo or following MDS or MDS/MPD. The cases are seen mainly in elderly and rare in children. There is often severe pancytopenia. They can show dysgranulopoiesis, dyserythropoiesis, and or dysmegakaryopoiesis. The blasts are positive for CD34 and pan-myeloid markers (CD13 and CD33). Frequently aberrant expression of CD56 and CD7 is seen. There is increased incidence of multidrug resistance glycoprotein: MDR-1. Multilineage dysplasia has adverse effect on remission.16

\section{Therapy related myeloid neoplasm}

They are seen after cytotoxic chemotherapy and or radiotherapy. They are of two types: alkylating agent and radiation therapy related and Topoisomerase II inhibitor related.

\section{Alkylating Agent/Radiation Therapy Related AML/ MDS}

They occur 5-6 years after initiation of treatment with alkylating agents or radiotherapy. The risks are related to age and also to cumulative dosage. Two-thirds of cases present as MDS. One-third of cases present as overt AML with MDS features. All myeloid cell lines affected.

Dyserythropoiesis, ring sideroblasts are seen in $60 \%$ of cases (one-third in excess of $15 \%$ of erythroid cells). They also show hypo granulation and nuclear hypolobation of granulocytes. Dysplastic megakaryocytes are seen increased in $25 \%$ of cases. Basophils are increased in $25 \%$ of cases. Auer rods are seen in a minority of cases. Bone marrow biopsy is hypercellular in $50 \%$ of cases, normocellular in $25 \%$, hypocellular in $25 \%$, and shows fibrosis in $15 \%$. The types of AML commonly developed include M2, M4, M5, $\mathrm{M} 6$, and M7.
Table 5: AML with MDS: (karyotype changes similar to MDS)

Common: $-7 / \operatorname{del}(7 q),-5 / \operatorname{del}(5 q),+8,+9,+11, \operatorname{del}(11 q), \operatorname{del}(12 p)$, $\mathbf{- 1 8},+\mathbf{1 9}, \quad$ del $(20 \mathrm{q}),+21$

Less common: $\mathrm{t}(2 ; 11), \mathrm{t}(1 ; 7), \quad 3 \mathrm{q} 21$ and $3 \mathrm{q} 26$

$\mathrm{t}(3 ; 21)(\mathrm{q} 21 ; \mathrm{q} 26)$ : usually therapy related, or associated with CML as a 2 nd event at blast crisis

$\mathrm{t}(3 ; 5)(\mathrm{q} 25 ; \mathrm{q} 34)$ is associated with mutilineage dysplasia

AML in Down syndrome

Blastic plasmacytoid dendritic cell neoplasm

Table 6: AML, not otherwise specified (NOS)

AML with minimal differentiation
AML without maturation
AML with maturation
Acute myelomonocytic leukaemia
Acute monoblastic and monocytic leukaemia
Acute erythroid leukaemia (erythroleukaemia (erythroid/myeloid)
and pure erythroid leukaemia)
Acute megakaryoblastic leukaemia
Acute basophilic leukaemia

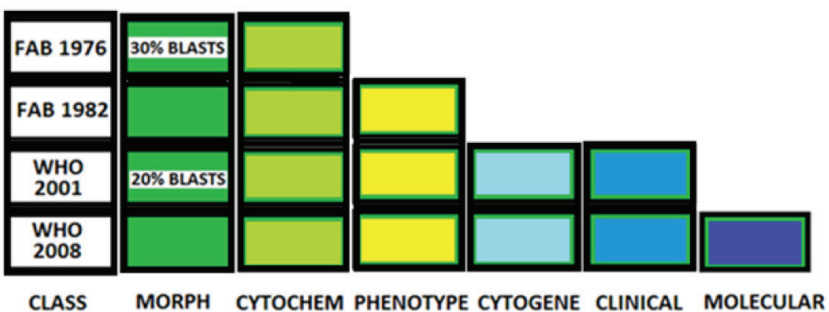

Figure 1: Evolution of AML Classifications.

Immunophenotype in these lesions include blasts that often express CD34+, CD33+, CD13+, frequent aberrant expression of $\mathrm{CD} 56+$ and $\mathrm{CD} 7+$. There is an increase incidence of MDR-1 expression in blasts. These lesions show increased cytogenetic abnormalities similar to de novo MDS, RCMD, RAEB. These include unbalanced translocations, deletions of chromosomes 5 and 7 (long arms), chromosomes 1, 4, 12, 14, 18, complex chromosomal abnormalities. They show poor response to therapy, poor survival is seen. ${ }^{17}$

\section{Topoisomerase II Inhibitor Related AML/MDS}

They are associated with epipodophyllotoxins and related compounds that target DNA-Topoisomerase II, examples etoposide and teniposide, also anthracyclines, such as doxorubicin and 4-epi-doxorubicin. They affect all age groups. They show shorter latency: 12-130 months (median: 33-34 months). Latency can be less than 6 months. They usually presents as overt AML without a previous MDS 


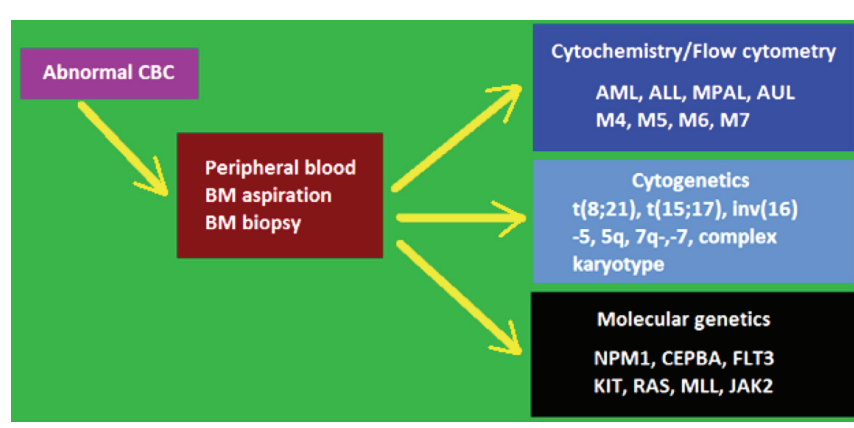

Figure 2: Flowchart for AML workup

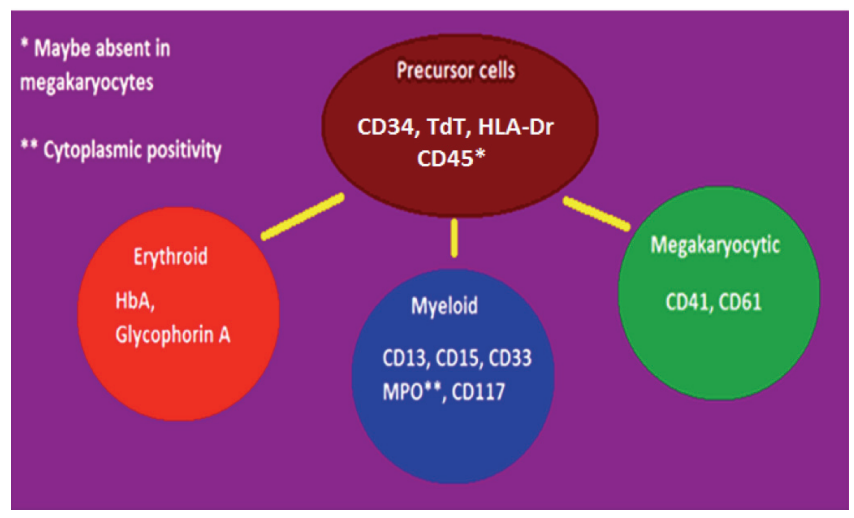

Figure 3: Useful myeloid phenotypic markers.

phase. There may be a significant monocytic component. Most are acute monoblastic or myelomonocytic, occasionally acute promyelocytic leukemia or acute megakaryoblastic leukemia. The bone marrow is usually hypercellular. Usually balanced translocations involving 11q23 (MLL gene) and primarily $\mathrm{t}(9 ; 11), \mathrm{t}(11 ; 19)$, and $\mathrm{t}(6 ; 11)$ are seen. Other translocations include $\mathrm{t}(8 ; 21), \mathrm{t}(3 ; 21)$, inv $(16), \mathrm{t}$ $(8 ; 16)$.. They usually show good initial response to therapy, but relapses frequent and survival variable (especially poor with 11q23).

\section{AML, not otherwise specified (AML NOS):}

They include AML without recurrent genetic abnormalities and those without any myelodysplasia, post therapy related or Down's syndrome association (fig.6 and table6). Promonocytes in AML monoblastic variant are considered equivalent to blasts. Two new entities acute basophilic leukaemia and acute panmyelosis with myelofibrosis have been included with AML NOS.

\section{Myeloid proliferations associated with Down's syndrome}

Transient myeloid abnormalities often occur with DS, though AML related with DS is also seen. About $10 \%$ of Down's syndrome show transient myeloproliferative disorder (TPD). The blasts are CD13, CD33 (myeloid) and CD41, CD61 (megakaryocytic) positive. The cases can be asymptomatic or show severe disease. Most regress

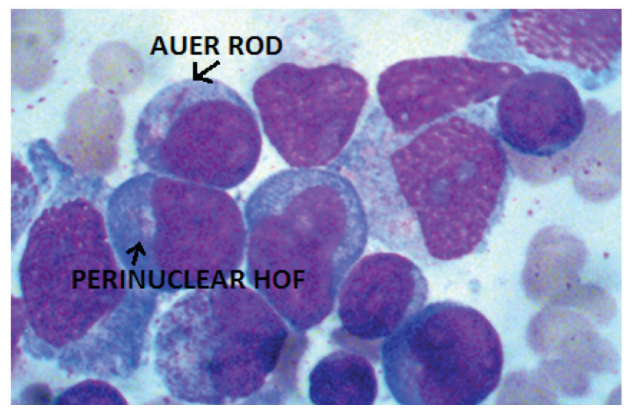

Figure 4: AML with $\mathrm{t}(8: 21)(\mathrm{q} 22 ; \mathrm{q} 22)$. Note: large blasts with nuclear indentation perinuclear hof and Auer rod (Wright stain, $\mathrm{X}$ 1000).

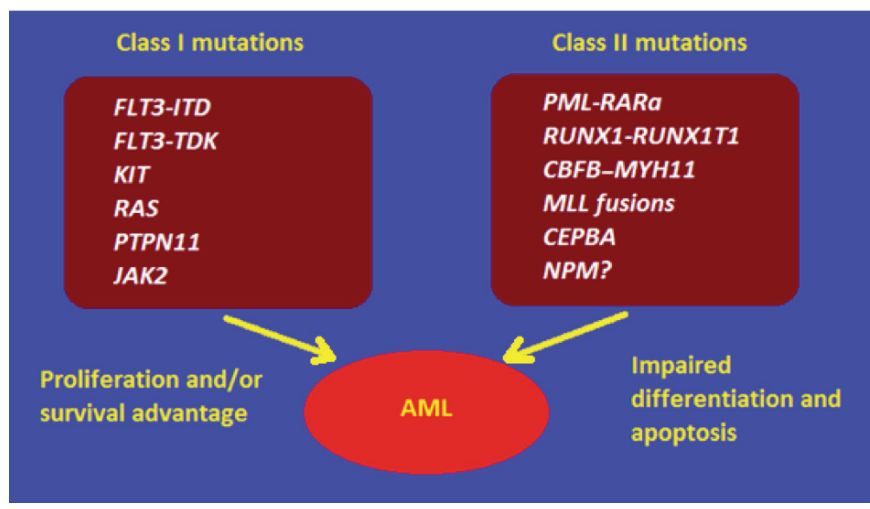

Figure 5: Mutation analysis in AML (Gilliland hypothesis).

spontaneously without any treatment. About 20-30\% progress to AML.

Down's syndrome (DS) is associated with acute leukaemia (fig.7). AML) M7 is 500 times more common in DS than normal children. Half of leukaemias in DS are AML. ALL is 40 times more common in DS. AMKL is more common and confers a better prognosis in Down's syndrome. GATA-1 mutation occurs early in DS and is associated with increased risk of future leukaemia. GATA-1 mutations in DS with AML show better response to therapy and better overall prognosis compared to non-DS children with AML. ${ }^{18}$

\section{Microarray analysis and specific targeted therapy for AML}

Microarray analysis or gene profiling involve using large numbers of up to 13,000 oligonucleotide gene probes. The aim is an attempt to try to study the pathogenesis, predict prognosis and sub classify the different AML variants into meaningful groups. Genes with poor prognosis have been identified like HOXB2, HOXB5, PBX3, HOXA4, and HOXA10. However microarray methods are still yet to replace standard genetic methods. ${ }^{19}$

Use of specific agents targeted against gain of function mutations like FLT3, JAK2 and cKIT are being developed using tyrosine kinase inhibitors The drugs include sorafenib, quizartinib, testaurtinib, midostaurin, pacritinib, PLX3397, 


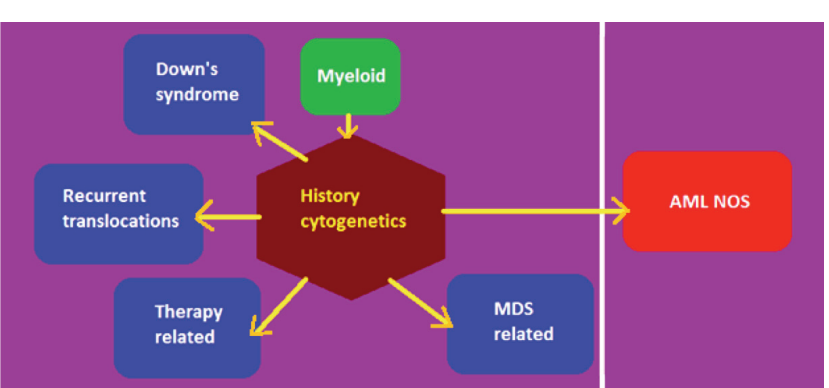

Figure 6: Clinical variants of AML (WHO 2008).

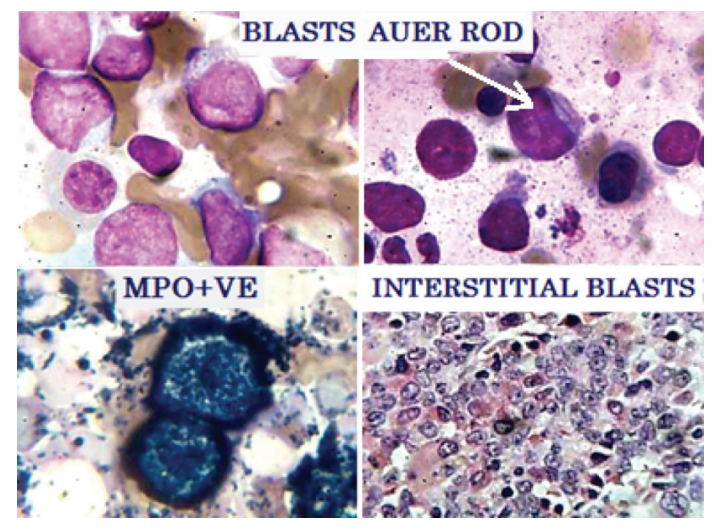

Figure 7: AML with Down's syndrome

and CCT137690. Aberrant proteins that are produced in AML like PLK1 can also be a target for specific therapy.20

\section{CONCLUSION}

The last decade has seen a large upsurge of interest and has resulted in many discoveries in the fields of acute myeloid leukaemias, cytogenetics and molecular genetics. A molecular classification of leukaemias is a distinct reality appearing in the distant horizon. Gene expression profiling, micro-RNA analysis, methylation analysis and whole genome sequencing analysis are expected to deliver more accurate descriptions of intricate molecular changes in AML. The data will help better understand the clinical behavior in distinct genetic groups resulting in better response to therapy and improved prognosis. The fields are exciting, it is hoped that all these events will lead to better understanding and management of these neoplasm, many of which still show dismal prognosis at present.

\section{REFERENCES}

1. Swerdlow SH, Campo E, Harris NL et al. WHO Classification of Tumours of Haematopoeitic and Lymphoid Tissues. IARC Press, Lyon 2008.

2. Bennett JM, Catovsky D, Daniel MT et al. Proposals for the classification of the acute leukaemias (FAB cooperative group). Br J Haematol 1976;33:451-8.

3. Bennett JM, Catovsky D, Daniel MT et al. Proposed revised criteria for the classification of acute myeloid leukaemia. Ann intern Med 1985;103:626-9.
4. Jaffe ES, Harris NL, Stein H, Vardiman JW. Pathology and Genetics Tumours of Haematopoeitic and Lymphoid Tissues, IARC Press, Lyon 2001.

5. Slovak Ml, Kapecky KJ, Cassileth PA et al. Karyotypic analysis predicts outcome of preremission and postremission therapy in adult acute myeloid leukaemia: a Southwest Oncology Group/Eastern Cooperative Oncology Group study. Blood 2000;96:4075-83.

6. Plesa A, Ciuperca G, Louvet Vet al. Diagnostic of the AML with immunophenotypical data, Math. Model Nat Phenom 2008;1:104-23.

7. Mrozek K, Heerema NA, Bloomfield CD. Cytogenetics in acute leukemia. Blood Rev 2004;18:115-36.

8. Bryd JC, Mrozek K, Dodge RK et al. Pretreatment cytogenetic abnormalities are predictive of induction success, cumulative incidence of relapse, and overall survival in adult patients with de novo acute myeloid leukemia: results from Cancer and Leukemia Group B (CALGB 8461). Blood 2002;100:4325-36.

9. Grimwade $\mathrm{D}$, Walker $\mathrm{H}$, Oliver $\mathrm{F}$ et al. The importance of diagnostic cytogenetics on outcome in AML: analysis of 1,612 patients entered into the CRC AML 10 trial. The Medical Research Council Adult and Children's Leukaemia Working Parties. Blood 1998;92:2322-33.

10. Kelly LM, Gilliland DG. Genetics of myeloid leukemias. Annu Rev Genomics Hum Genet 2002;3:179-98.

11. Verhaak RG, Goudswaard CS, van Putten W et al. Mutatations in nucleophosmin NPM1 in acute myeloid leukemia (AML): association with other gene abnormalities and previously established gene expression signatures and their favorable prognostic significance. Blood 2005;106:3747-54.

12. Boissel N, Renneville A, Biggio V et al. Prevalence, clinical profile, and prognosis of NPM mutations in AML with normal karyotype. Blood 2005;106:3618-20.

13. Preudhomme C, Sagot C, Boissel N et al. Favorable prognostic significance of CEPBA mutations in patients with de novo acute myeloid leukemia: a study from the Acute Leukemia French Association (ALFA). Blood 2002;100:2717-23.

14. Bacher U, Haferlach C, Kern W, Haferlach T, Schnittger S. Prognostic relevance of FLT-TDK mutations in AML; the combination matters. Analysis of 3082 patients. Blood 2008;111:2527-37.

15. Paschika P, Marcucci G, Ruppert AS et al. Adverse prognostic significance of KIT mutations in adult acute myeloid leukemia with $\operatorname{inv}(16)$ and $t(8 ; 21)$ : a Cancer and Leukemia Group B Study, J Clin Oncol 2006;24:3904-11.

16. Aber Da, Stein AS, Carter NH, Ikle D, Forman SJ, Slovak ML., Prognostic impact of acute myeloid leukemia. Importance of detecting recurring genetic abnormalities and multilineage dysplasia on survival. Am J Clin Pathol 2003;119:672-80.

17. Michels SD, McKenna RW, Arthur DC, Brunning RD. Therapyrelated acute myeloid leukemia and myelodysplastic syndrome; a clinical and morphological study of 65 cases: Blood 1985;65:136472.

18. Lange BJ, Kobrinsky N, Barnard DR et al. Distinctive demographic, biology, and outcome of acute myeloid leukemia and myelodysplastic syndrome in children with Down's syndrome. Blood 1998;91:60815 .

19. Estey EH, Faderal FH, Kantarjian HM, 2008. Hematologic malignancies: Acute leukemias, 1998, Springer, 39-40. Eleftheria H, Gergios G, Leonidas B, Evangelos B. Gene mutations and molecularly targeted therapies in acute myeloid leukemia. Am J Blood Res 2013;1:29-51.

20. Eleftheria H, Gergios G, Leonidas B, Evangelos B. Gene mutations and molecularly targeted therapies in acute myeloid leukemia. Am J Blood Res 2013;1:29-51. 